\section{Images in Clinical Medicine}

Wien Klin Wochenschr (2004) 116/21-22: 715

(C) Springer-Verlag 2004 wiener klinische wochenschrift

the middle european journal

of medicine

Printed in Austria

\title{
Acute basilar artery occlusion
}

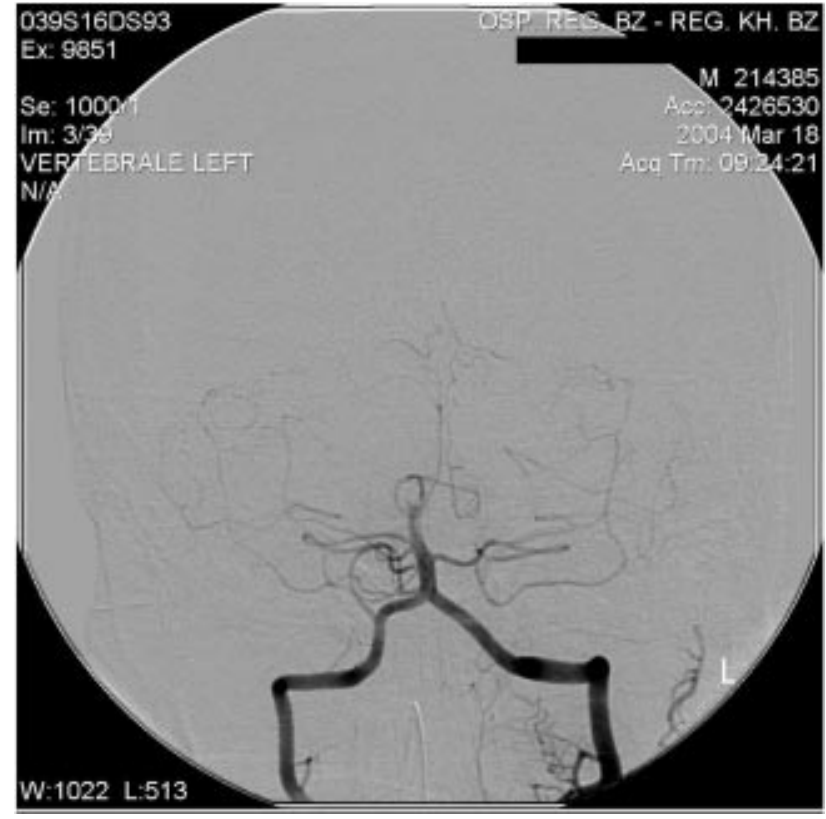

Fig. 1

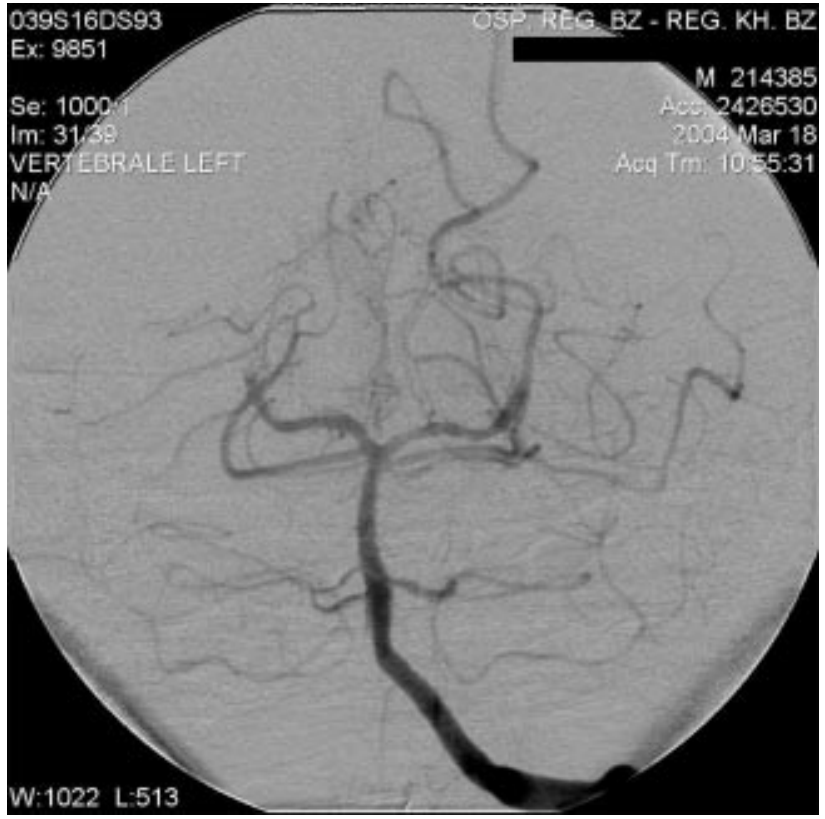

Fig. 2

Basilar artery occlusion usually has a very poor outcome and is associated with a high mortality rate [1]. We report a case of a 38-year-old man who was brought to hospital deeply unconscious with a Glasgow Coma Score of 3 and wide unresponsive pupils. CCT and angiography revealed complete occlusion of the basilar artery (Fig. 1). Recanalisation by intraarterial thrombolysis with $800.000 \mathrm{U}$ of urokinase was effective 120 minutes after onset of symptoms (Fig. 2). The patient recovered completely within 32 hours. In contrast to the carotid territory, there are no placebo-controlled studies proving the efficacy of thrombolytic treatment for the vertebrobasilar territory. Several uncontrolled series however, indicate that intraarterial thrombolysis reduces mortality of patients with basilar artery occlusion [2].

Bernadetta Moser, Peter Zanon, Gianpiero Bonatti, Norma Decaminada, and Georg Röggla

\section{References}

1. Ezaki Y, Tsutsumi K, Onizuka M, Kawakubo J, Yagi N, Shibayama A, Toba T, Koga H, Miyazaki H (2003) Retrospective analysis of neurological outcome after intra-arterial thrombolysis in basilar artery occlusion. Surg Neurol 60: 423-429

2. Brandt T (2002) Diagnosis and thrombolytic therapy of acute basilar artery occlusion: a review. Clin Exp Hypertens 24: 611622

Key words: Basilar artery occlusion, thrombolysis.

Correspondence: Dr. Bernadetta Moser, Department of Intensive Care Medicine, Hospital of Bolzano, 39100 Bolzano, Italy, E-mail: bernadetta.moser@asbz.it 